\title{
The Effect of Broiler Market Age on Performance Parameters and Economics
}

\section{Author(s)}

Schmidt GS

Researcher Embrapa Suínos e Aves

\section{Mail Address}

GS Schmidt

Caixa Postal 21

89.700-000. Concórdia, SC, Brazil

E-mail: schmidt@cnpsa.embrapa.br

\section{Keywords}

Broiler, cost, integrated companies, performance.

\section{ABSTRACT}

In the present study, 35 farmers contracted by an integration company were selected. Each farmer owned an average of seven poultry houses, and housed six flocks per year, with a total of 4.0 million housed broilers. Birds were grouped into 5 market ages $(M A 1=<43$, $43<\mathrm{MA} 2=<44,44<\mathrm{MA} 3=<45,45<\mathrm{MA} 4=<46, \mathrm{MA} 5>46$ days), and the following parameters were measured: average flock body weight (AFW), feed conversion ratio (FCR), livability (L), production efficiency index (PEI), production cost, and farmer's gross margin. MA significantly influenced all parameters, except production cost $/ \mathrm{kg}$ broiler. The effects of farm and farm*MA interaction were not significant. Each day of MA increase resulted in increases of $68.43 \mathrm{~g}$ and 0.039 units in AFW and FCR, respectively. PEI was $4.0 \%$ lower in MA5 as compared to MA1, thereby reducing farmer's compensation in $11.89 \%$ per reared broilers. Production costs were not different among market ages, partially due to a reduction from 16.86 (MA1) to $14.62 \%$ (MA5) in the farmer's participation in the total cost. The results show that a new farmer's compensation index that included MA is necessary to calculate farmer's margin.

\section{INTRODUCTION}

Genetic improvement, in addition to maximizing live performance in poultry production, has allowed a reduction of age to market. The definition of genetic line and market age is associated to market demands for different product types, as well as to production costs. During the last decades, eating habits have globally changed, with a strong preference for meat cuts and processed meat, and consequently the market of chicken cuts has exceeded the whole-bird market. This has lead to later-finishing birds for the production of commercial cuts because larger birds present higher yield (Mendes et al., 1993).

The current genetic lines present different growth curves (Scheuermann et al., 1999; Mendes, 2001), as well as different performance parameters within the same line, according to market age and weight. Oliveira et al. (2003) evaluated 5 different broilers genetic lines, and observed significant differences at 42 days of age for body weight $(154 \mathrm{~g})$, feed conversion ratio (0.03 units), and carcass yield (1.95\%). Within the same genetic line, differences of $492 \mathrm{~g}, 0.14$ units, and $3.09 \%$ were found for body weight, feed conversion ratio, and carcass yield between 42 and 49 days of age. Livability and fat deposition are negatively affected by increase in broiler market age (Cotta, 1994).

Therefore, according to literature, increasing market age affects production efficiency, which may result in higher production costs. From the processors' perspective, the higher added value obtained when trading meat cuts has justified this increase in market age. However, 
one of the factors considered for the determination of the price paid to the farmer is the production efficiency index, and therefore increasing broiler market age will only benefit the farmer if there is some kind of bonus paid.

Data on the impact of market age variation on technical and economic results of integrated companies are scarce in literature. Therefore, this study aimed at determining the impact of different market ages on performance and economic parameters.

\section{MATERIAL AND METHODS}

The present study was carried out in an integrated company from January to December, 2004. The company processed 120,000 broilers per day. A total number of 35 farmers were selected to evaluate live and economic performance of broilers as a function of market age (MA). Each farm housed, in average, 6 flocks during that period, with a total of 4 million oneday-old chicks housed at an average density of 13 birds/ $\mathrm{m}^{2}$. In average, broilers housed measured 1,200 $\mathrm{m}^{2}$, and were equipped with an automatic feeding system, $(60 \%)$ or bell $(40 \%)$ drinkers, foggers, and fans.

Average market age was different within and between farms, and each flock was considered an experimental unit. Flocks were grouped for analysis according to market age as: $M A 1=<43,43<M A 2=<44$, $44<M A 3=<45,45<M A 4=<46$ e MA5 $>46$ days.

The parameters average flock market weight $(A F W)$, feed conversion ratio (FCR), livability (L), production efficiency index (PEI=DWG/FCR) and production cost $/ \mathrm{kg}$ broiler were used to assess live performance and economics. Production cost was determined using day-old chick cost, feed cost, farmer's compensation (which depends on flock performance) and operational costs (inputs, transport, technical service, etc.), which were considered fixed for all market ages.

Farmer's gross margin was calculated based on the company's compensation table, which takes into account PEI and broiler average price. In the simulation, the average price for live broilers in the São Paulo stock exchange in February of 2007 was used ( $R \$ 1.40$ ).

A completely randomized experimental design was applied, considering the factors farm (35), with six flocks each, market age, and interaction Farm * MA. Regression analysis was used to evaluate the effect of MA on AFW, FCR, and PEI. Data were analyzed using the statistical procedures of SAS software package (SAS, 1996).

\section{RESULTS AND DISCUSSION}

The means estimated for each parameter as a function of market age (MA), are presented in Table 1. MA significantly influenced all evaluated parameters, except for final cost $/ \mathrm{kg}$ broiler, and the effect of the Farm*MA interaction was not significant. The mean market age of groups MA1, MA2, MA3, MA4, and MA5 were $42.29,43.58,44.68,45.60$, and 47.84 days, respectively (Table 1 ).

The effect of MA on AFW was positive and linear, and allowed the classification of $M A$ in three significantly different groups: early (MA1 and MA2), intermediate (MA3), and late (MA4 and MA5) birds, indicating significant body weight increase as birds aged. The growth curve after 42 days of age (Figure 1 ) is represented by the regression equation AFW = $2.042+68.43 * M A$, showing a 68.43g increase in AFW per day of MA increase. These results are consistent with most literature findings (Scheurmann et al., 1999; Mendes, 1993; Mendes et al., 2001); however, the difference between MA1 and MA5 (266g) was lower than the $492 \mathrm{~g}$ obtained by Oliveira et al. (2003) for broilers between 42 and 49 days of age.

Livability (L) reduction as a function of MA was significant, reaching a $0.72 \%$ difference between MA1 and MA5, which agrees with the findings of Cotta (1994). Considering the average $L$ of contemporary flocks, which is usually determined in a 30-day period, is utilized as a correction factor of the $L$ obtained in

\begin{tabular}{|c|c|c|c|c|c|}
\hline \multirow[t]{2}{*}{ Parameter } & \multicolumn{5}{|c|}{ Market age } \\
\hline & MA1 & MA2 & MA3 & MA4 & MA5 \\
\hline Average market age (days) & 42.29 & 43.58 & 44.68 & 45.60 & 47.84 \\
\hline Average weight (g) & $2.085^{c}$ & $2.167^{c}$ & $2.265^{b}$ & $2.407^{a}$ & $2.351^{\mathrm{a}}$ \\
\hline Livability (\%) & $96.85^{a}$ & $97.44^{\mathrm{ab}}$ & $96.68^{b c}$ & $96.63^{c}$ & $96.15^{c}$ \\
\hline Feed conversion ratio & $1.84^{a}$ & $1.89^{b}$ & $1.91^{\mathrm{bc}}$ & $1.94^{c}$ & $2.01^{d}$ \\
\hline Efficiency index & $262.07^{a}$ & $256.83^{a b}$ & $256.35^{b}$ & $255.13^{c}$ & $251.48^{c}$ \\
\hline Final cost/kg broiler (R\$) & 1.346 & 1.356 & 1.347 & 1.343 & 1.382 \\
\hline Compensation/bird housed & $0.227^{a}$ & $0.226^{a}$ & $0.213^{b}$ & $0.212^{b}$ & $0.202^{c}$ \\
\hline
\end{tabular}

Means followed by different letters in the same row are significantly different $(p<0.05)$. 


\section{Schmidt GS}

The Effect of Broiler Market Age on Performance

Parameters and Economics

the slaughtered flock, significant MA differences affect the economic performance of the farmer.

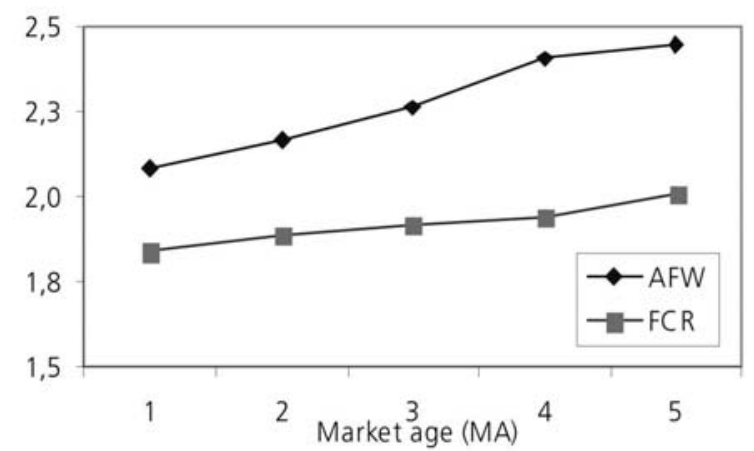

Figure 1 - Effect of market age group (MA) on average flock weight $(\mathrm{AFW})$ and feed conversion ratio (FCR).

The effect of MA on FCR was positive and linear, with an $8.7 \%$ between MA1 and MA5. From the live production perspective, this is considered negative as higher FCR causes a direct increase in production costs. This effect was represented by the regression equation $\mathrm{FCR}=1.87+0.039 * \mathrm{MA}$ (Figure 2), determining a $2.1 \%$ increase in FCR per day of MA increase. The 0.17 difference in FCR between MA1 and MA5 is higher than the 0.03 reduction obtained by Oliveira et al. (2003), when comparing market ages of 42 and 49 days. This difference is probably due to the better management conditions and lower number of birds evaluated under experimental conditions by those authors.

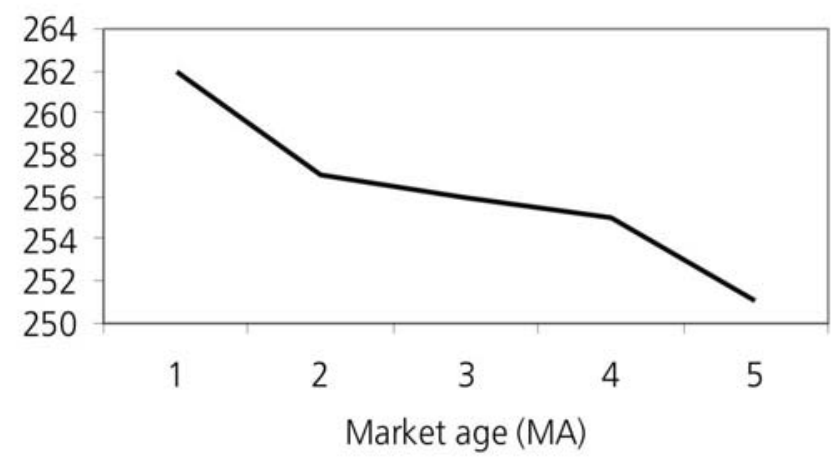

Figure 2- Effect of market age group (MA) on production efficiency index (PEI).

PEl, which is often used to determine farmer's compensation, was reduced in $4.0 \%$ when MA1 was compared to MA2. Results show that after 45 days of age, MA significantly influences farmer's compensation index. The gradual reduction of farmer's compensation/ housed bird (Table 1), which reached $11.0 \%$ between MA5 (0.202) and MA1 (0.227) indicates the negative effect of MA on farmer's compensation.

The hypothesis that higher MA would result in higher farmer's compensation as a function of higher meat volume/m2 was not confirmed, indicating that the impact of FCR and mortality increase is higher than the extra weight gain obtained as MA increased.

Considering the results obtained in the present study and a facility to house 16,000 birds, the farmer would have a $R \$ 400$ reduction in his/her gross margin per flock, when MA1 (R\$3,632) is compared to MA5 ( $R \$$ 3,232 ). In addition, housing capacity would be reduced in one flock for every three years. However, there are models that use other indexes to determine farmer's compensation, allowing for the correction of live performance as a function of market age.

The negative effect of market age on live performance did not significantly influence production cost per kg of broiler, which is consistent with the results obtained by Oliveira et al. (2003). However, this lower impact on production cost was due to a variation from $16.86 \%$ (MA1) to $14.62 \%$ (MA5) in the farmer's participation in the composition of the final cost.

\section{CONCLUSION}

The results of the present study show the need to include market age in farmer's compensation indexes as a mechanism to adjust the compensation factor, thereby preventing the farmer from being penalized by the negative impact of market age on live performance.

\section{REFERENCES}

Cotta JTB. Aspectos zootécnicos, microbiológicos e sensoriais da qualidade de carcaças de frango. In: Lima, HD. Abate e processamento de frangos. Campinas: Fundação Apinco de Ciência e Tecnologia Avícola; 1994. p.77-95.

Mendes AA. Efeito da linhagem e idade de abate sobre o rendimento de carcaça de frangos de corte. Revista Sociedade Brasileira de Zootecnia 1993; 22(3):466-472.

Mendes AA. Rendimento e qualidade da carcaça de frangos de corte. Anais da Conferência Apinco de Ciência e Tecnologia Avícola; 2001; Campinas, São Paulo. Brasil. p.79-100.

Oliveira RP. et al. Desempenho produtivo e rendimento de carcaça e partes de cinco linhagens de frango de corte em diferentes idades de abate. Revista Brasileira de Ciências Avícola 2003; Supl 3:3.

SAS Statistical Analysis Sistems User's Guide: Stat. Version 6. 4th ed. Cary: SAS Institute; 1966. v.2. 